\title{
8
}
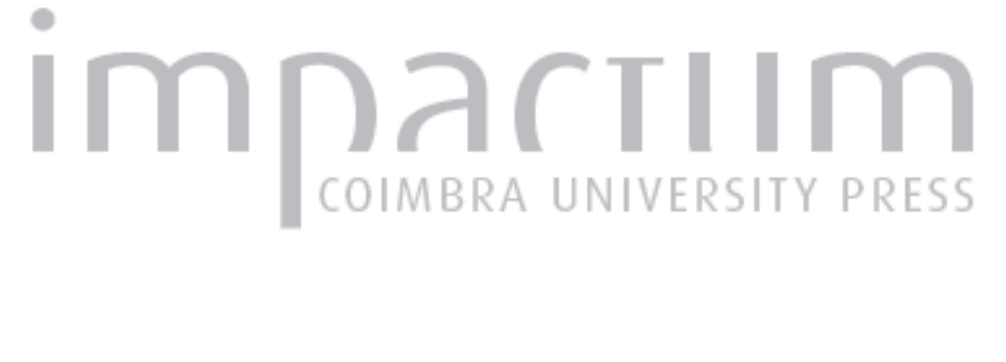

\section{Património e museus em contexto rural: dos lugares de memória aos territórios do lazer e do turismo}
Autor(es):
Carvalho, Paulo

Publicado por: Faculdade de Letras da Universidade de Coimbra

URL persistente:

URI:http://hdl.handle.net/10316.2/32304

DOI:

DOI:http://dx.doi.org/10.14195/0870-4112_10_11

Accessed : $\quad$ 26-Apr-2023 11:39:20

A navegação consulta e descarregamento dos títulos inseridos nas Bibliotecas Digitais UC Digitalis, UC Pombalina e UC Impactum, pressupõem a aceitação plena e sem reservas dos Termos e Condições de Uso destas Bibliotecas Digitais, disponíveis em https://digitalis.uc.pt/pt-pt/termos.

Conforme exposto nos referidos Termos e Condições de Uso, o descarregamento de títulos de acesso restrito requer uma licença válida de autorização devendo o utilizador aceder ao(s) documento(s) a partir de um endereço de IP da instituição detentora da supramencionada licença.

Ao utilizador é apenas permitido o descarregamento para uso pessoal, pelo que o emprego do(s) título(s) descarregado(s) para outro fim, designadamente comercial, carece de autorização do respetivo autor ou editor da obra.

Na medida em que todas as obras da UC Digitalis se encontram protegidas pelo Código do Direito de Autor e Direitos Conexos e demais legislação aplicável, toda a cópia, parcial ou total, deste documento, nos casos em que é legalmente admitida, deverá conter ou fazer-se acompanhar por este aviso.

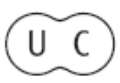



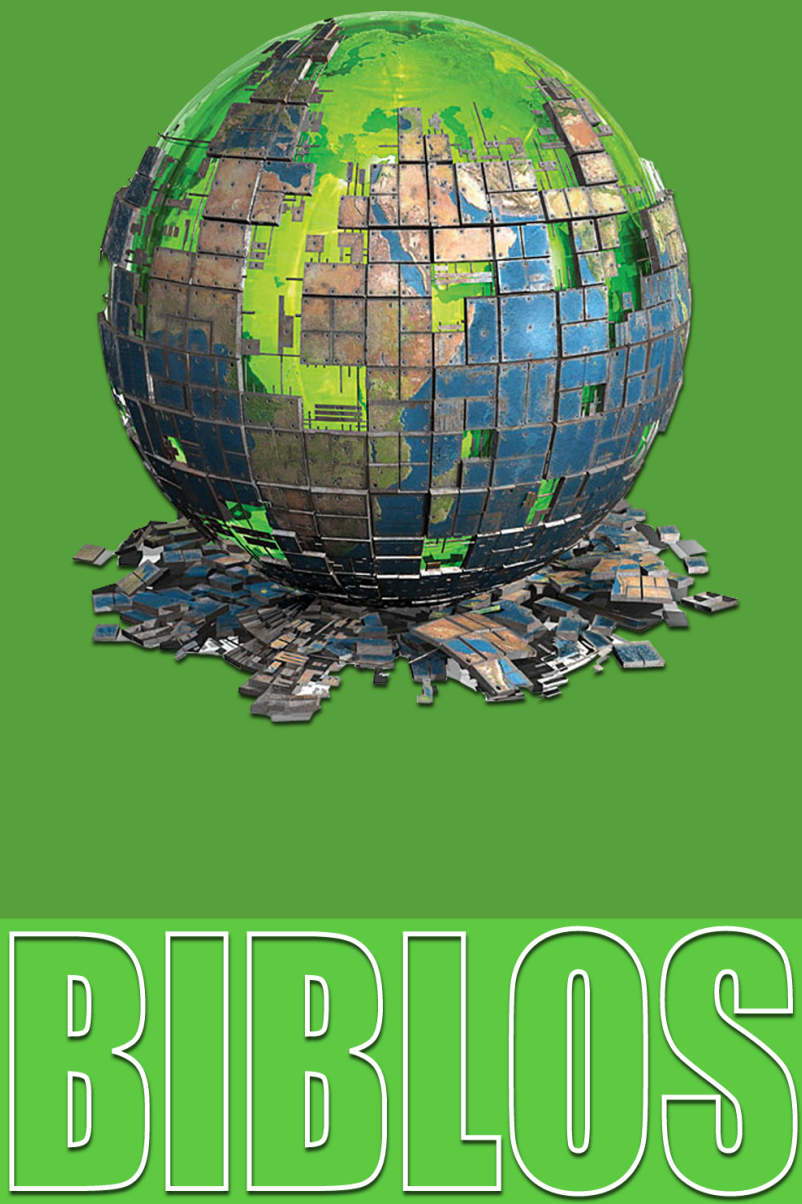

$\frac{\text { REVISTA DA FACULDADE DE LETRAS }}{\text { UNIVERSIDADE DE COIMBRA }}$ 
Biblos, n. s. X (2012) $\ldots-\ldots$

Paulo Carvalho

Centro de Estudos de Geografia e Ordenamento do Território (CEGOT)

Universidade de Coimbra

\title{
PATRIMÓNIO E MUSEUS EM CONTEXTO RURAL: dos lugares de memória aos territórios do lazer e do turismo*
}

\begin{abstract}
Resumo
O alargamento da noção de património e os instrumentos para a diversificação, revitalização e requalificação rural configuram elementos matriciais de importantes iniciativas de salvaguarda e valorização do património rural (ou em contexto rural) com a crescente vinculação ao lazer e turismo, de que os projetos museológicos são parte.

Reconhecendo que os museus rurais integram de forma crescente centros de documentação, lojas, serviços de cafetaria/restauração, atividades formativas e pedagógicas, entre outras, que, assim, complementam a sua oferta e respondem aos novos interesses dos visitantes, pretendemos com este artigo deixar um contributo para discutir, na perspetiva geográfica, a importância atual do património cultural e dos museus em contexto rural (temática que terá como suporte geográfico da componente empírica o caso de Portugal).
\end{abstract}

Palavras-Chave: Património Rural, Desenvolvimento Rural, Museus Rurais, Portugal.

\begin{abstract}
The enlargement of the concept of heritage and the instruments for rural diversification, revitalisation and rehabilitation are crucial components of important initiatives in view of the safeguarding and upgrading of rural heritage (or heritage in a rural context) with a growing linkage to leisure and tourism, of which museological projects are part.

Recognizing that rural museums increasingly integrate documentation centres, shops, cafeteria/catering services, training and educational activities, among others, which thus complement their offer and respond to new interests of visitors, we intend with this article to offer a contribution to a discussion, from a geographical perspective, of the current importance of cultural heritage and museums in a rural context (with the Portuguese case as the geographical focus of the empirical part of the analysis).
\end{abstract}

Keywords: Rural Heritage, Rural Development, Rural Museums, Portugal.

* O presente texto resulta da nossa participação no $6^{\circ}$ Congresso Internacional Turismo e Desenvolvimento (Málaga, julho de 2012). 


\section{Património e desenvolvimento rural}

O património emerge como temática de grande visibilidade e relevância estratégica no âmbito do desenvolvimento dos territórios e das populações, em ambientes geográficos de geometria variável, e sob diferentes pretextos: requalificação e revitalização territorial, melhoria das condições e qualidade de vida das populações, reconstrução de memórias e identidades, processos de mediação educativa (educação patrimonial), e integração dos lugares na esfera dos lazeres turísticos, entre os mais significativos.

$\mathrm{Na}$ ótica dos principais documentos orientadores e normativos internacionais, entre convenções, recomendações, resoluções e restantes atos, através de instituições de referência como por exemplo a UNESCO, o ICOMOS e o Conselho da Europa, as tendências evolutivas do património permitem sublinhar: o crescimento e alargamento do campo patrimonial; a maior relevância das dimensões imateriais e dos ambientes rurais e vernaculares; a visibilidade do geopatrimónio e da biodiversidade; a valorização do contexto paisagístico (uma vez que o quadro natural e construído interfere de forma significativa na perceção estática ou dinâmica dos bens); a aproximação em relação aos cidadãos (incentivar a participação dos cidadãos nas diversas tarefas relacionadas com a proteção e a valorização do património e estabelecer com eles uma nova relação); a democratização do acesso à cultura; a responsabilidade crescente atribuída ao poder local (designadamente no contexto dos instrumentos de gestão territorial); o incremento das estratégias de cooperação e a construção de redes; o caráter utilitário (no sentido de encontrar/atribuir função); e ainda o reconhecimento da educação patrimonial (Carvalho, 2011).

Portanto, estamos perante um conceito marcado por uma acentuada plasticidade temporal e espacial (uma vez que os seus elementos matriciais configuram escalas, tipologias e contextos diversos) e um incontornável nomadismo científico (como se depreende da expressão "ciências do património").

A integração do património nos processos de desenvolvimento económico, social e cultural dos territórios e das populações revela uma tipologia ampla e complexa de estratégias/intervenções, que inclui os lazeres turísticos, designadamente o turismo cultural e ecológico (lugares, rotas e redes), os museus e os parques temáticos, os eventos 
culturais, os estatutos de proteção e a classificação de lugares, as operações de requalificação urbanística e ambiental, entre as mais relevantes (Carvalho, 2010).

As perspetivas e as intervenções da União Europeia no âmbito do mundo rural refletem a transição de uma conceção agrícola, centrada na agricultura e direcionada para os agricultores e suas organizações, para uma conceção pós-agrícola alicerçada na valorização de novas atividades como suporte essencial da renovação e viabilidade do mundo rural, que por sua vez acompanha o maior interesse da população urbana em relação aos territórios rurais. Esta última, de cariz territorial, norteada para o território e para o conjunto da população rural, considera que a política agrícola deve ser integrada no quadro de uma política de desenvolvimento rural que impulsione a diversificação de atividades e dote os territórios rurais de infraestruturas e equipamentos suficientes para que a população se mantenha nos espaços rurais em condições de qualidade (Moyano Estrada, 2006) e responda aos desafios da sociedade do lazer, e assim configura novas oportunidades para salvaguardar, valorizar e fruir o património, como demonstram diversos programas e iniciativas sobretudo na última década, através de exemplos paradigmáticos entre lugares, rotas e redes.

No presente, a política europeia de desenvolvimento para os espaços rurais reconhece a especificidade dos territórios e do seu potencial de recursos, e reflete orientações e objetivos diferenciados, através de medidas de apoio direcionadas para os setores agrícola e florestal (tendo presente as preocupações de competitividade e eficiência produtiva, e as exigências ambientais), para a diversificação da base económica e para a revitalização social.

A aplicação desta política diferenciada nas suas iniciativas e destinatários deverá sedimentar uma ruralidade com mais dignidade e qualidade de vida, e contribuir para salvaguardar e valorizar os recursos estratégicos do mundo rural, como é o caso do património cultural.

$\mathrm{O}$ interesse cultural relevante do mundo rural, de acordo com valores de "memória, antiguidade, autenticidade, originalidade, raridade, singularidade ou exemplaridade", e a sua inclusão no património, reflete bens materiais (imóveis e móveis) e imateriais, "mas também, quando for caso disso, os respetivos contextos que, pelo seu valor de testemunho, possuam com aqueles uma relação interpretativa e informativa", como assinala a Lei $\mathrm{n}^{\circ} 107 / 2001$, de 8 de setembro (que esta- 
belece as bases da política e do regime de proteção e valorização do património cultural português).

O património rural material imóvel assume diferentes dimensões ou expressões como por exemplo as estruturas edificadas de maior simbolismo e expressão patrimonial, entre edifícios de natureza militar (atalaias, castelos, muralhas e fortificações), religiosa (mosteiros e conventos), e civil (palácios, palacetes, casas brasonadas e solarengas) de forma individual ou em conjunto; as construções com menor pretensão artística e arquitetónica mas igualmente relevantes (como os imóveis para habitação e pequenas edificações relacionadas com a devoção religiosa); os caminhos antigos de ligação entre lugares, de acesso aos terrenos de cultivo e aos espaços florestais, de circulação do gado; as estruturas de apoio à circulação (terrestre - nas vertentes pedestre, rodoviária e ferroviária; fluvial e marítima) e as suas obras de arte (pontes, pontões, fontenários); as igrejas, capelas e ermidas; as estruturas produtivas pré-industriais (fornos de carvão, telha e cal, engenhos - papel e açúcar -, moinhos, azenhas, lagares); as gramáticas de pedra (muros, socalcos, curraletas); os sistemas de irrigação e de adução de água (poços, noras, engenhos, levadas, aquedutos e fontenários); os imóveis de serviços públicos (de habitação como as casas da guarda florestal e dos cantoneiros, e de apoio como os anexos das casas florestais e os depósitos de ferramentas da Junta Autónoma de Estradas); as construções relacionadas com as atividades agrícolas, pecuárias e florestais tradicionais (palheiros, celeiros, adegas, espigueiros, eiras, pombais, abrigos de pastores, cisternas, canais e levadas para armazenar e conduzir água). Em sentido mais global, a paisagem, quando construída pelas populações rurais e capaz de manifestar uma relação harmoniosa e equilibrada com o suporte físico, assumindo uma evidente dimensão cultural, é também uma forma incontornável de património material (as paisagens vinhateiras do Alto Douro e da Ilha do Pico, em Portugal, reconhecidas como de valor universal pela UNESCO, são dois exemplos paradigmáticos deste conceito).

De igual modo, é necessário considerar as estruturas e os equipamentos relacionados com as atividades de pendor industrial, como, por exemplo, a lavra ativa em minas (ferro, volfrâmio, ouro, cobre), a tecelagem e a fiação, a fileira da cortiça e do papel, e ainda os edifícios ligados a figuras de relevo na vida local ou nacional, em áreas como a política, a ciência, as artes (pintura, escultura, música) e as letras, 
e também aqueles que albergaram serviços e funções públicas como, por exemplo, escolas, igrejas (capelas e ermidas), casas que serviram de sede do poder (político e judicial).

Os bens culturais móveis suscetíveis de integrar o património cultural repartem-se por "espécies artísticas, etnográficas, científicas e técnicas, bem como espécies arqueológicas, arquivísticas, audiovisuais, bibliográficas, fotográficas, fonográficas". As formas de expressão no mundo rural incluem, para além dos sítios de interesse arqueológico, os objetos do quotidiano, do espaço de produção (ferramentas, utensílios e alfaias agrícolas) ao espaço de vida familiar (vestuário, mobiliário, peças utilitárias de barro, esmalte, louça e vidro), e ainda os utensílios de atividades em contexto rural, desde os estabelecimentos de comércio e "serviços", aos espaços pré-industriais e industriais.

Os bens imateriais configuram "realidades que, tendo ou não suporte em coisas móveis ou imóveis, representam testemunhos etnográficos ou antropológicos com valor de civilização ou de cultura com significado para a identidade e memória coletivas". Estão neste caso, as "expressões orais de transmissão cultural e os modos tradicionais de fazer, nomeadamente as técnicas tradicionais de construção e de fabrico e os modos de preparar os alimentos" (Lei n. ${ }^{\circ}$ 107/2001), entre outros. No mundo rural, destacam-se as técnicas e os saberes-fazer no âmbito de atividades como a agricultura, a criação de gado/pecuária, a silvicultura, o artesanato e outras artes e ofícios tradicionais; as músicas e as festividades; os momentos mais marcantes do ciclo etnográfico (matança do porco, descamisada, apanha e moagem da azeitona), as tradições orais, entre outras.

A gastronomia merece também realce neste domínio, com o reconhecimento de produtos tradicionais genuínos e singulares, através de medidas normativas orientadas para a sua valorização (por exemplo, os estatutos de denominação de origem protegida e denominação de origem controlada), e de formas voluntárias de organização/associação tendo em vista defender e promover esses produtos, como é o caso das confrarias (CARVALHO, 2012).

\section{Museus em contexto rural: salvaguarda e fruição de património(s)}

O alargamento da noção de património foi acompanhado de orientações e instrumentos para a diversificação, revitalização e requali- 
ficação rural que por sua vez estão na base de importantes iniciativas de salvaguarda e valorização do património rural (ou em contexto rural) com crescente vinculação ao lazer e turismo, de que os projetos museológicos são parte.

Em Portugal, na última década e meia, ganharam visibilidade intervenções como, por exemplo, Aldeias Históricas (Beira Interior), Aldeias do Xisto (Pinhal Interior), Aldeias de Água ou Ribeirinhas (Alqueva), Aldeias Históricas e Vilas do Alentejo e Aldeias Vinhateiras (Douro). Para além destas, apoiadas em instrumentos de desenvolvimento nacionais e regionais (com cofinanciamento da União Europeia através dos fundos estruturais), como foi o caso do Programa do Potencial de Desenvolvimento Regional (que esteve na origem do Programa das Aldeias Históricas, em 1994-1999), das Ações Integradas de Base Territorial (que alavancaram as intervenções nas Aldeias do Xisto, Aldeias Vinhateiras, Aldeias Históricas e Aldeias de Água, em 2000-2006), importa considerar diversas outras iniciativas alicerçadas em instrumentos de natureza setorial em particular as que decorreram do Programa LEADER e ainda as relacionadas com as áreas da cultura e turismo que permitiram a concretização de inúmeros projetos museológicos rurais (ou em meio rural).

O Museu Rural no parque temático do Arnado (Ponte de Lima), no âmbito de uma intervenção de valorização ou requalificação de margens ribeirinhas com a manutenção de paisagens rurais e a sua recuperação para utilizações de caraterísticas lúdicas e culturais; os núcleos sede, de investigação e de gastronomia do Ecomuseu da Serra da Lousã (Lousã); o Museu Judaico de Belmonte (figura 1), o Museu da Geodesia (Vila de Rei), o Museu do Piódão (figura 2), o Complexo Monumental de Idanha-a-Velha (que inclui diversos espaços museológicos como sítios arqueológicos e monumentos musealizados, museus de história e arqueologia, e museus mistos e pluridisciplinares), o Museu do Côa (figura 3) e Mértola (Vila Museu), são alguns exemplos de iniciativas museológicas com o apoio de programas públicos nacionais e comunitários.

A crescente iniciativa de criação de museus e espaços museológicos rurais não pode ser dissociada do alargamento do conceito de museu e das práticas museológicas, dos novos territórios do lazer lúdico e cultural, e dos desafios ou oportunidades de desenvolvimento sobretudo em territórios com maior potencial de recursos endógenos vinculados 


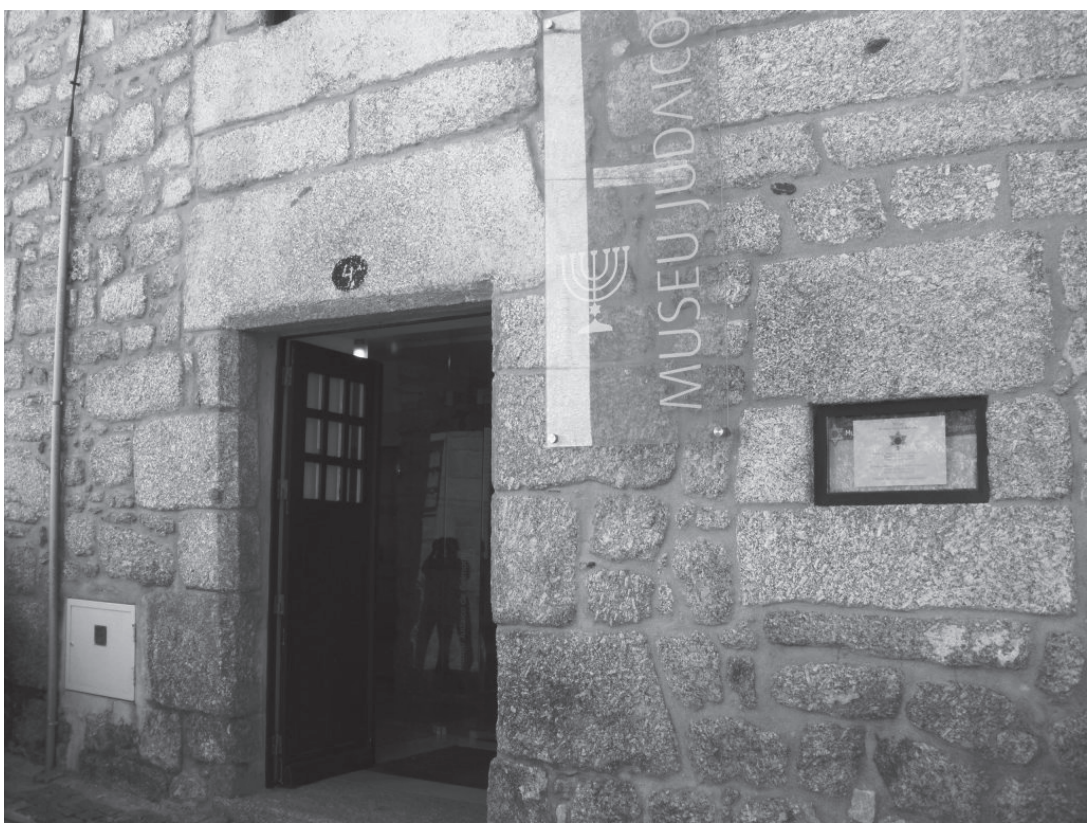

Figura 1 - Museu Judaico (Belmonte, 2009)

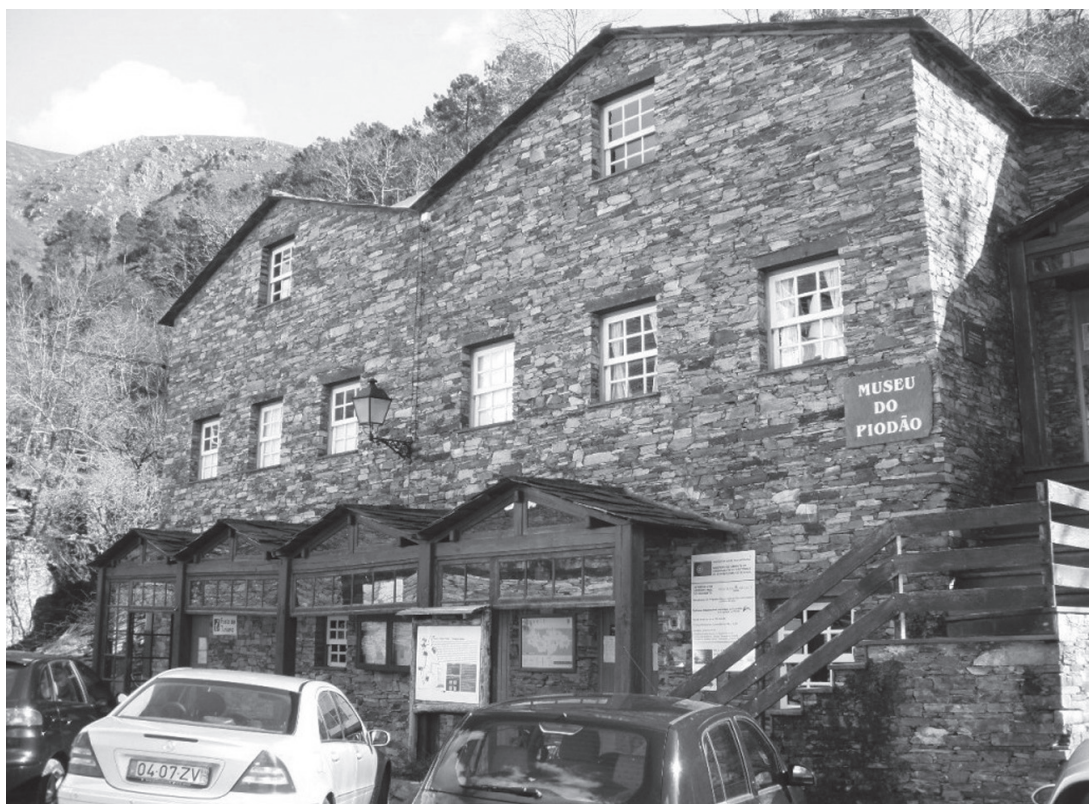

Figura 2 - Museu do Piódão (Arganil, 2012) 


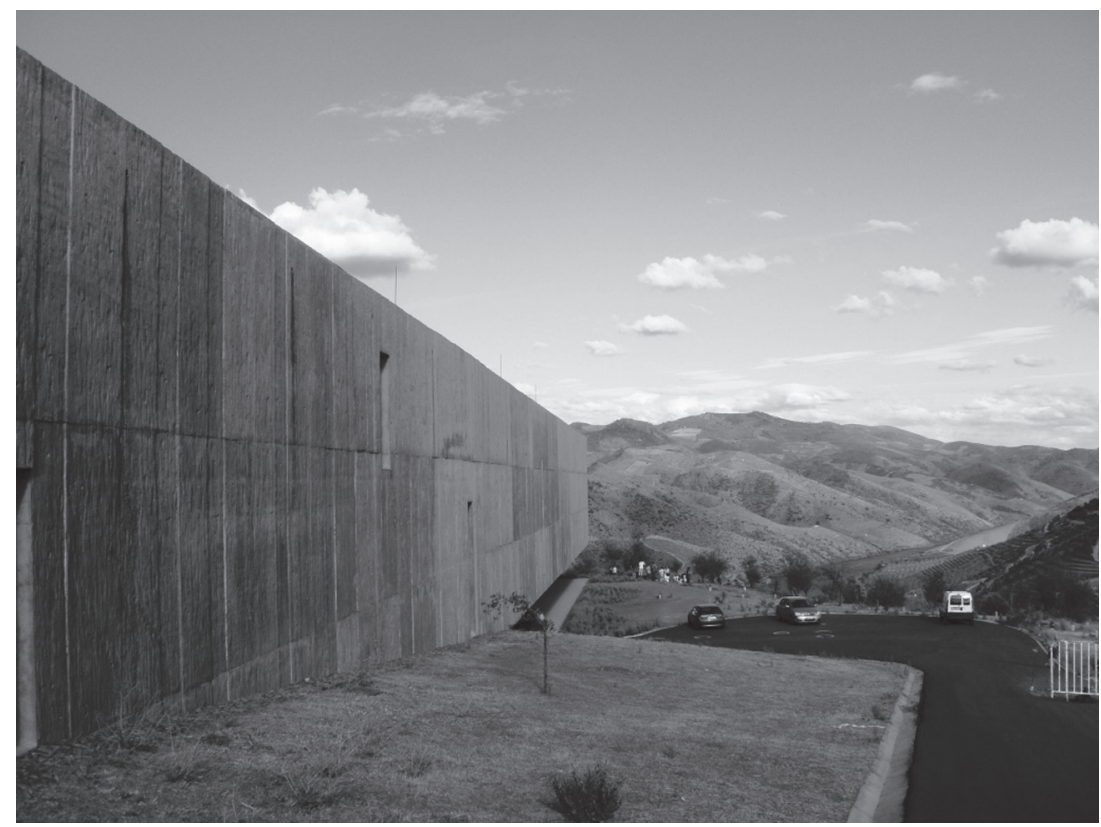

Figura 3 - Museu do Côa (Vila Nova de Foz Côa, 2011)

ao património. A ligação ao desenvolvimento local, uma vez que os museus (tal como as rotas e as redes patrimoniais) são considerados fatores de construção de futuro em matéria de desenvolvimento local na medida em que, de forma planeada e com inovação, podem valorizar os recursos endógenos, criar cadeias de valor acrescentado também com a participação da população local e, assim, promover dinâmicas locais sustentáveis.

As novas formas de atuar em museologia envolvem o alargamento da noção de património, a valorização e o papel central da paisagem enquanto matriz cultural, a investigação da realidade cultural do território numa perspetiva de interdisciplinaridade (Carvalho, 2003), o envolvimento da população, segundo uma preocupação de partilha de poderes, e a "[...] ideia de realçar os valores locais dentro de uma perspetiva de cultura integrante de todos os valores" (a cultura como uma vivência global integrada), como refere Jorge (2001). No registo de Primo (1999), a "Museologia Tradicional" é aquela que se exerce dentro de um edifício, com uma coleção, para um público determinado, exercendo uma função educadora (educação formal), enquanto a "Nova 
Museologia" é exercida dentro de um território, trabalhando o património cultural com uma comunidade participativa.

Na génese e evolução das formas de expressão da "nova museologia" é evidente a influência do pensamento e da atividade pioneira desenvolvida por Georges-Henri Rivière, nomeadamente a criação dos parques naturais franceses. Mais do que túmulos onde se fossilizavam os objetos de arte, ou depósitos de peças, misturadas entre si, normalmente segundo critérios decorativos e estéticos, o grande mestre Rivière pensava que os museus deviam ser fontes vivas e testemunhos de cultura(s).

Como sublinha Pessoa (2001), o conceito de parque natural, com origem na Alemanha, no final da década de 20 do século passado, procura preservar aspetos de algumas regiões rurais onde se mantinha uma relação harmoniosa das ações humanas, protegendo pontualmente alguns aspetos mais significativos da flora e da fauna e tentando manter atividades tradicionais da população que estavam na origem da paisagem criada.

Já anteriormente haviam surgido na Escandinávia os museus ao ar livre, reconstituindo aldeias características e mostrando atividades tradicionais das populações nórdicas, que evoluíram rapidamente para novos padrões da sociedade tecnológica moderna (Carvalho, 2002).

É através da evolução dos parques naturais, que em França adquirem a sua melhor expressão como instrumentos de ordenamento do território e de pedagogia do ambiente, que se consolidam as ideias de Rivière sobre o ecomuseu, conceito que, no entanto, só apareceu em 1971 na conferência geral do ICOM, em Grenoble - graças a Hugues de Varine Boham, sucessor de Rivière na direção desse organismo (fundado em 1946), e que, dessa forma, designou a conceção museológica evolutiva através da qual se revela a natureza e a evolução do homem no território onde vive (Pessoa, 2001).

Do ecomuseu, das suas salas de exposição nova e dinâmica, partem os percursos de descoberta da Natureza e do Homem, por onde os visitantes poderão admirar e aprender "in loco" o que o museu thes ensinou (Pessoa, 2001). Uma série de atividades completam o ecomuseu, que envolve desde o princípio a participação ativa da população (quer através da cedência de peças para as exposições quer trabalhando nas diferentes estruturas que funcionam no seu âmbito, como sejam as oficinas artesanais), a quem, afinal, se destina em primeiro lugar. 
Assim revelam-se as componentes fundamentais do ecomuseu: o museu do tempo e o museu do espaço; o primeiro é o palco do relato cronológico da génese e evolução da paisagem, através de peças selecionadas para estabelecer o fio condutor do museu; o segundo, tradução espacial dos ensinamentos do museu do tempo, envolve os valores autênticos e originais da cultura e natureza em contexto próprio, afinal toda a região em causa.

A evolução do conceito francês "écomusée" colocou em evidência a crescente dificuldade em envolver todos os pressupostos enunciados e os contextos definidos pelos seus teorizadores (Hudson, 1996), nomeadamente a componente de participação ativa e quotidiana da população, o que levou Pessoa (2001), reconhecendo essas dificuldades de aplicar a Designação de ecomuseu original, a sugerir a vantagem de utilizar o conceito de "museu de interpretação da paisagem".

Em relação ao universo de museus rurais (ou em contexto rural) mais recentes, a investigação científica permite evidenciar alguns casos que ajudam também a compreender a crescente amplitude e complexidade das realidades museológicas em Portugal.

O Museu da Cortiça (Silves) surgiu em 1999, no âmbito de um investimento de empresários locais para refuncionalizar a Fábrica do Inglês (antiga Fábrica Avern, Sons \& Barris - figura 4) e apresenta uma exposição permanente sobre o património industrial corticeiro do Algarve, dando a conhecer como se processa a transformação da casca do sobreiro.

Este Museu, galardoado com o prémio de melhor Museu Industrial da Europa em 2001 (ano em que recebeu mais de 100 mil visitantes), é composto por espaços variados como as salas de interpretação e a de audiovisuais, oficina transformadora, oficinas de serralharia, ferraria e de correeiro, casas da máquina e da prensa, centro de documentação, arquivo e reserva e oficina de restauro.

Contudo, dificuldades financeiras estão na origem do encerramento deste espaço museológico (em maio de 2010) e do complexo de animação turística que albergava também espaços de restauração e espetáculos, com inevitáveis impactos externos negativos no que diz respeito ao movimento de visitantes (turistas e excursionistas) e atividades culturais na antiga capital do Algarve, assim como ao futuro do acervo (maquinaria e documentação) sobre a história da indústria da cortiça (considerado um dos mais importantes a nível mundial). 


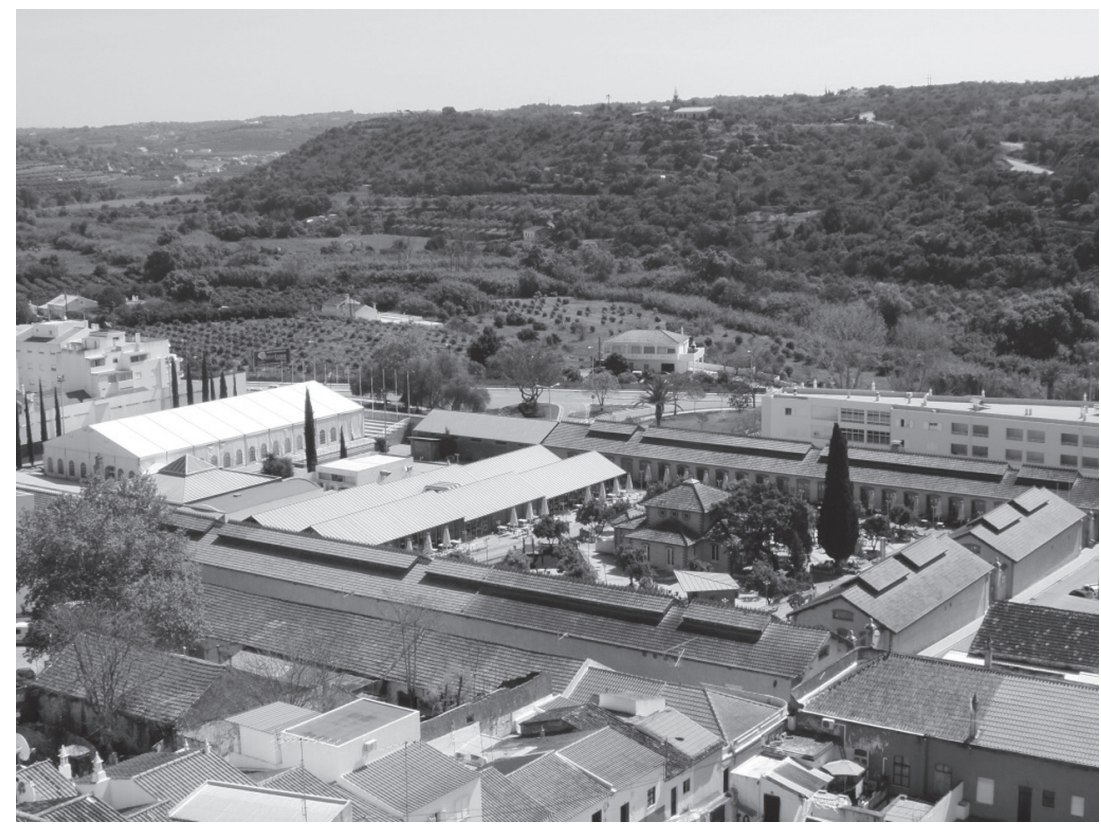

Figura 4 - Fábrica do Inglês

(segundo imagem captada do castelo de Silves, 2010)

Entretanto, o acervo documental foi transferido para o Arquivo Distrital de Faro, ao abrigo de um protocolo entre a administração da Fábrica do Inglês e a Secretaria de Estado da Cultura, através da Direcção-Geral de Arquivos, numa altura em que parte do complexo está à venda em hasta pública.

A temática industrial está também retratada em exemplos de implantação urbana como o Museu do Papel (Santa Maria da Feira) e o Museu dos Lanifícios (Covilhã). O Museu do Papel está instalado num espaço que integra "três antigos imóveis papeleiros, do séc. XIX, em Paços de Brandão - a Fábrica do Engenho Novo, a Fábrica de Custódio Pais e a Fábrica dos Azevedos. É um Museu dedicado ao fabrico do papel, com um espaço de produção manual e um espaço industrial onde se mostra o processo de fabrico em contínuo. Destaca-se ainda uma coleção de Marcas de Água e um espólio constituído por peças oriundas de diferentes fábricas do país" (Lifecooler, 2012). O Museu de Lanifícios, gerido pela Universidade da Beira Interior, "está dividido 
pelos núcleos da Real Fábrica de Panos, da Real Fábrica Veiga e das Râmolas de Sol. É considerado um dos melhores museus da Europa nesta área. O primeiro preserva a memória da manufatura do Estado, aqui mandada instalar pelo marquês de Pombal em 1764. As estruturas e os objetos conservados evocam os primórdios da industrialização, que recorria ainda à água das ribeiras da serra como força motriz principal. O segundo núcleo, correspondente a uma fase tecnológica mais avançada e que estava ligada à maquinaria a vapor. Caldeiras de vapor da antiga Fábrica Veiga, as antigas instalações tintureiras, com as suas fornalhas e os poços cilíndricos para tingir as lãs, são algumas das coisas que se podem ver neste museu" (Lifecooler, 2012).

De acordo com dados oficiais relativos ao período de 2007 a 2009, este espaço museológico recebeu quase oito mil visitantes/ano, os quais são provenientes de forma maioritária de municípios localizados a Sul da Serra da Estrela, com destaque para Lisboa, Sintra, Seixal e Oeiras, todos da região da Grande Lisboa (Mendes, 2011). Através de um estudo comparativo com o Museu do Pão (Seia), Mendes (2011) conclui que quase dois terços dos visitantes do Museu de Lanifícios são turistas (e utilizam empreendimentos turísticos, sobretudo estabelecimentos hoteleiros, como meio de alojamento), enquanto no Museu do Pão apenas cerca de um terço dos visitantes foram considerados turistas. Importa referir ainda que o Museu de Lanifícios apresenta um público com um nível académico mais elevado do que os inquiridos do Museu do Pão, o que pode indicar que os visitantes têm maior interesse em matérias culturais e patrimoniais.

O Museu do Pão (Seia - figuras 5 e 6) é uma iniciativa privada com génese em 1996, através de um grupo de professores e empresários com bastante interesse pela gastronomia tradicional serrana, que durante os seis anos seguintes reuniram todo o espólio e edificaram o espaço museológico (Amado, 2011).

Situado na Quinta Fonte do Marão, num edifício recuperado e ampliado para o efeito, o Museu do Pão (que abriu ao público em 2002), apresenta diversas dimensões ou valências, nomeadamente salas expositivas ("Ciclo do Pão", "Arte do Pão", "Pão Político, Social e Religioso"), espaço lúdico-pedagógico (com elevada interação, através da recriação do ciclo do pão e da sua confeção), bem como espaços de comércio (padaria e antiga mercearia) e serviços (bar-biblioteca e restaurante). 

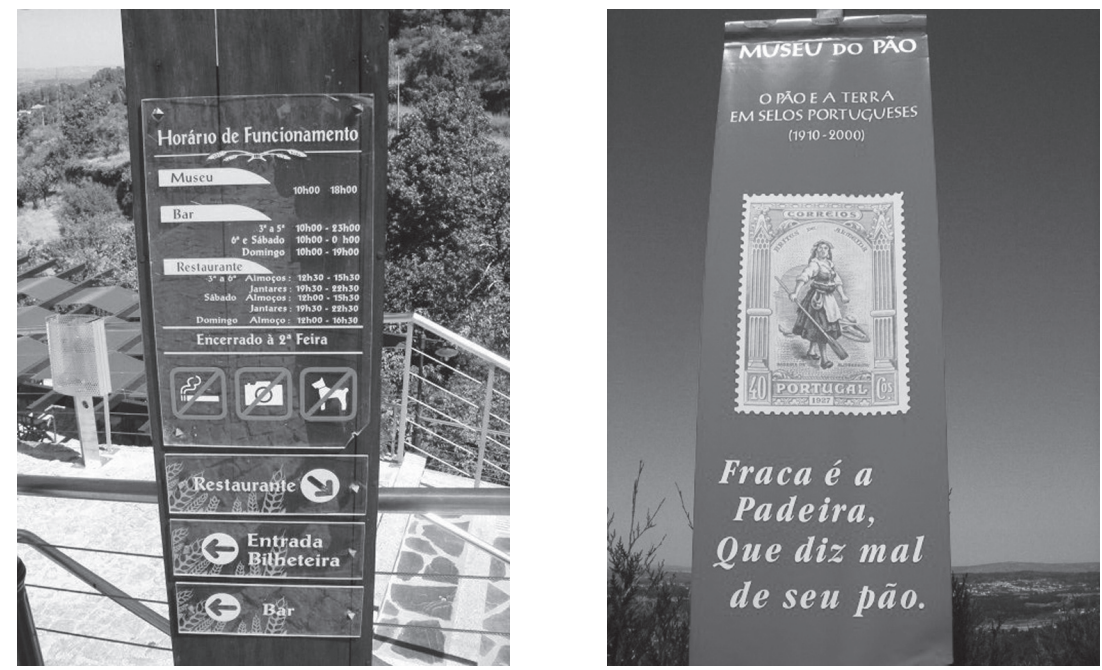

Figuras 5 e 6 - Museu do Pão (Seia, 2006)

O número de visitantes do Museu do Pão, entre 2003 e 2010, tem sido superior aos $100 \mathrm{mil} / \mathrm{ano}$ (com algumas exceções), o que revela o interesse suscitado por esta unidade sobretudo em relação ao público português (que representa 95\% do total de visitantes). Amado (2011) na dissertação de mestrado em Geografia que dedicou ao Museu do Pão, refere que $97 \%$ dos visitantes é de origem nacional e destes cerca de $65 \%$ é proveniente da Região Centro (o que está em linha com as conclusões da investigação de Mendes, em 2011), sublinha que cerca de $68 \%$ dos inquiridos afirmam que apesar da passagem pelo Museu do Pão, este não foi o principal destino da sua viagem (destacando-se a Serra da Estrela como o principal motivo de visita dos inquiridos) e conclui que apenas $22 \%$ dos inquiridos assinala problemas relacionados com a visita ao museu (com destaque para as acessibilidades). A apreciação global dos inquiridos sobre o papel do museu e a qualidade dos serviços prestados é boa e muito boa.

O Museu Mineiro do Lousal (Alentejo) é parte de um projeto integrado de intervenção social iniciado na segunda metade dos anos 90 (do século XX), tendo em vista recuperar espaços e equipamentos esvaziados das suas funções originais, resgatar memórias vivas bem como preservar e valorizar o património existente na plenitude das suas dimensões material e intangível. 
"Descoberto no início dos anos oitenta, século XIX, o jazigo do Lousal só conheceu intensa exploração a partir da sua concessão à empresa belga Mines et Industries. As pirites cupríferas extraídas foram, desde então, base segura da indústria química adubeira fomentada, a partir dos anos trinta (séc. XX), pela Campanha do Trigo. As décadas de cinquenta - sessenta, corresponderam, também, ao período em que se modernizou a cadeia operatória da mina, processo apoiado num conhecimento cada vez mais aprofundado da geologia das massas de minério e na progressiva mecanização da produção que atingiu, pelos anos setenta um ritmo da ordem das 100 t/hora de produto comercial, decaindo, desde então, o ritmo de produção. Com o encerramento das minas em 1988, toda a estrutura social e económica erigida, durante décadas, em torno dos minérios, desmorona-se. Privada da principal fonte de sustento, a maior parte da população viu-se forçada a procurar fora o trabalho que o lugar lhes negou. Abandonam-se casas e equipamentos" (Brandão, 2011: 1).

"O Museu polinucleado Mineiro do Lousal é o único em Portugal, que aproveita as antigas instalações e infraestruturas da mina para a construção dos seus núcleos. Este Projeto de Revitalização do Complexo Mineiro do Lousal (RELOUSAL), foi promovido não só pela SAPEC Imobiliária S.A [última e atual proprietária da mina], mas também pela Câmara Municipal de Grândola e pela Fundação Frederic Velge; a responsabilidade científica do Projeto ficou a cargo da Associação Portuguesa de Arqueologia Industrial (APAI). A primeira fase deste projeto consistiu na reabilitação da antiga Central Elétrica e a construção de um Centro de Interpretação. A segunda (ainda em andamento) irá caracterizar-se pela animação e musealização de uma antiga galeria da mina conhecidas como projeto da "Descida à Mina". Este museu consegue transformar-se a si e à Aldeia do Lousal num espaço de cultura, e vivência social, numa área edificada com testemunhos geológicos datados de 2000 a.C. (...)" (Chaínho, 2011: 4).

"Aideia de um Ecomuseu para a região de Barroso resulta da consciência, mas também da preocupação de salvaguardar um património, nas suas múltiplas componentes, natural, cultural e socioeconómica, com uma finalidade de contribuir para o desenvolvimento das populações. Por isso se adota um conceito de Museu do Território, o qual repousa na valorização dos seus recursos chave: as populações e o património natural e cultural. Procurando manter os níveis de sustentabilidade 
do desenvolvimento e alcançar mesmo uma revitalização agrícola do território, o Ecomuseu de Barroso, em colaboração com a Comunidade envolvida, procura incentivar os processos de diversificação das atividades, nomeadamente as associadas ao ecoturismo e outras que propiciem uma melhoria socioeconómica e permitam encontrar novos motivos de fixação à terra" (Teixeira, 2006: 3).

Centrada no concelho de Montalegre (Alto Trás-os-Montes), esta proposta museológica é orientada para a participação dos visitantes, "situa objetos no seu contexto, preserva conhecimentos técnicos e saberes locais, consciencializa e educa acerca dos valores do património cultural; implica interpretar os diferentes espaços que compõem uma paisagem; permite desenvolver programas de participação popular e contribui para o desenvolvimento da comunidade. O Ecomuseu de Barroso tem dado continuidade ao trabalho de pesquisa sistemática, já iniciado, tarefa que permite inventariar a globalidade de património construído do território de Montalegre, tendo em vista a posterior salvaguarda e valorização dos espécimes selecionados pelo seu particular interesse patrimonial. A análise das construções associadas à conservação e à transformação dos produtos tem permitido um melhor conhecimento da arquitetura popular da região, nomeadamente dos canastros, dos moinhos, dos fornos, das fontes, dos pisões e dos lagares, entre outros edifícios de produção agrícola que contribuirão para o reencontro com a identidade cultural local" (Teixeira, 2006: 3).

Para além do estudo de iniciativas museológicas, a investigação científica tem dedicado especial atenção ao domínio dos projetos e propostas de museus. Dos diversos casos retratados na bibliografia nacional, destacamos a proposta de musealização de fornos de carvão vegetal na freguesia do Ramalhal (Torres Vedras), onde esta atividade económica é ainda muito relevante. A produção de carvão vegetal está documentada de forma mais evidente na aldeia de Vila Facaia, "na qual subsiste um conjunto de seis fornos que labora esta atividade. Esta produção apresenta duas fases de implementação no território, visíveis através do estudo arquitetónico dos fornos onde o carvão é produzido. Estes fornos apresentam duas fases de construção. A primeira remonta aos anos 40/50 do século XX, a segunda fase de implementação remonta aos anos 70/80 do final do século $\mathrm{XX}$, aquando do impulso industrial que se fez notar após o 25 de Abril. O carvão vegetal é obtido através da queima da madeira. Inicialmente a matéria-prima utilizada 
era o sobro e o azinho, vindos do Alentejo. Mais recentemente começou a ser utilizada a madeira disponível da freguesia, o eucalipto. É neste âmbito que surge a necessidade de preservar este tipo de produção, através de uma proposta de musealização de sítio. Esta reflexão resulta da preocupação em salvaguardar este espaço e atividade característico da freguesia, não deixando de valorizar a população envolvida e o património cultural e natural" (Santos, 2009: 3).

Através destes (e de outros) exemplos é evidente a diversidade de realidades e contextos dos museus rurais (ou em contexto rural) - figuras 7 e 8 , o que está relacionado com a amplitude crescente do conceito de museu e das práticas a ele vinculadas.

No mesmo sentido, importa explicar que a integração dos museus nas estratégias do desenvolvimento rural decorre da abertura dos territórios rurais a novas funções (como as relacionadas com os lazeres turísticos) e novos atores (desde empreendedores a visitantes - excursionistas ou turistas) bem como da importância dos vínculos, memórias e identidades na perspetiva das relações entre a sociedade e os territórios (do quotidiano, da afetividade, do lazer, entre outros).

As profundas alterações económicas, sociais, culturais e políticas, sobretudo desde meados do século $\mathrm{XX}$, tiveram consequências incontornáveis no espaço rural. Apesar das múltiplas ruralidades e das especificidades dos contextos e dimensões dos processos de

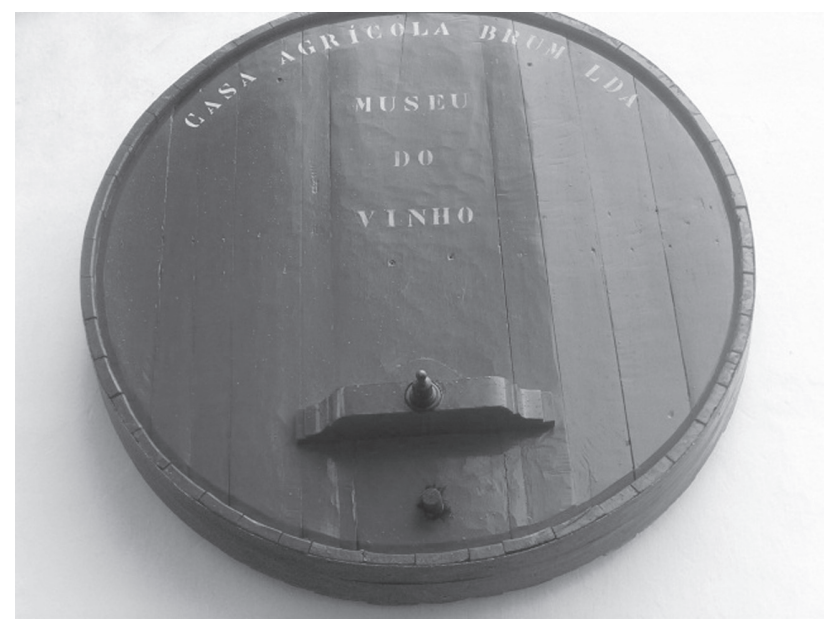

Figura 7 - Museu do Vinho (Biscoitos, Ilha Terceira, 2008) 


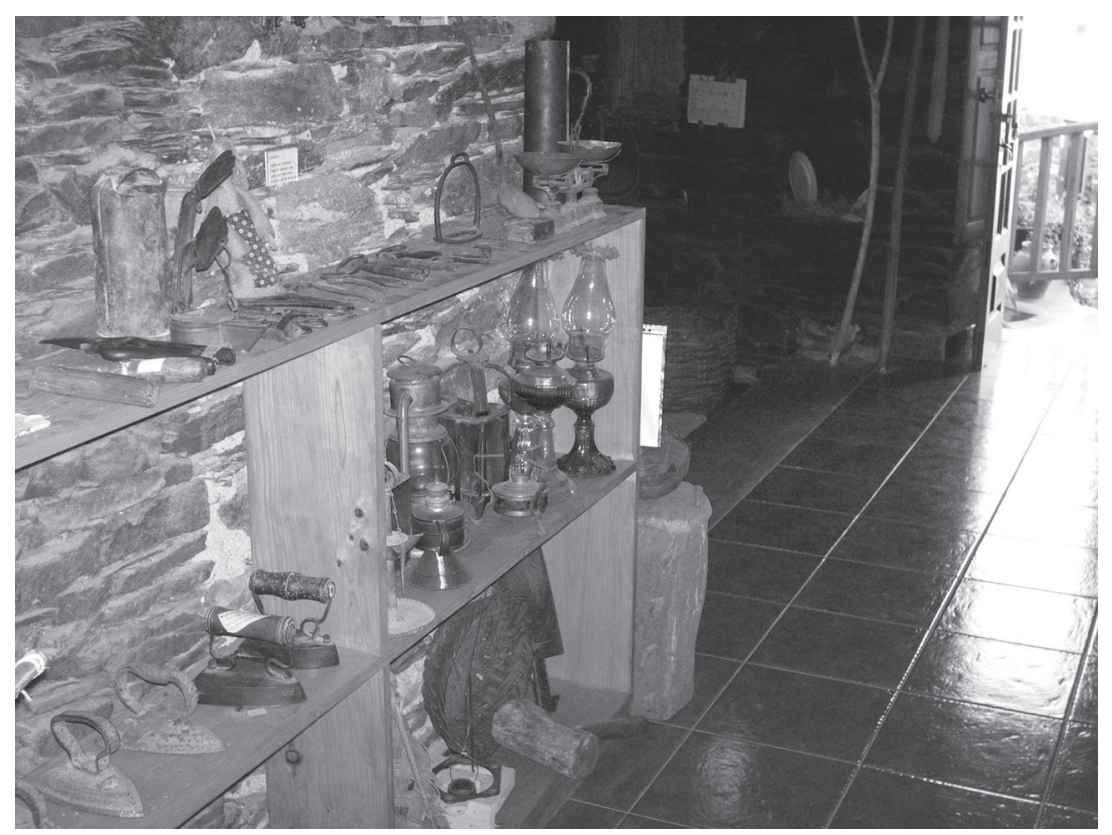

Figura 8 - Museu Monsenhor Augusto Nunes Pereira

(Fajão, Pampilhosa da Serra, 2010)

mudança nacionais, regionais e locais, os sinais de transformação são incontornáveis: redução significativa do emprego no setor primário, mobilidade demográfica e desvitalização económica e social progressiva do meio rural (em particular nos contextos mais afastados dos espaços urbanos), despovoamento e nova organização do sistema de lugares, abandono crescente da paisagem rural na perspetiva das suas componentes funcionais, estigmas negativos e reduzida autoestima em torno do rural e dos rurais. A este sentido e contexto geral de dificuldades, problemas estruturais e horizontes pouco animadores, é necessário contrapor algumas dinâmicas positivas relacionadas quer com iniciativas vinculadas a recursos e capitais endógenos quer com ações, capitais e fluxos urbanos que de forma pontual atenuaram ou contrariaram as referidas tendências de fundo. Os recursos patrimoniais e paisagísticos, associados a escalas de valor (económico, estético, simbólico, terapêutico, entre outros) configuram vértices de centralidade para explicar as tendências recentes em matéria de ocupação, utilização e modos de viver do e no espaço rural. 
O abandono dos campos e da paisagem rural é acompanhado de preocupações em particular no que diz respeito à salvaguarda da memória coletiva a eles ligada, como sublinha Brito (2003: 65) através da seguinte ideia: "quando os equipamentos e processos de trabalho deixam de ser aqueles que marcaram, ao longo de décadas, séculos mesmo, os quotidianos, eles vão-se destacando como objetos de memória e referentes, alvo de todo o tipo de intervenções que vão no sentido da sua patrimonialização".

A ativação destes objetos (que, tendo perdido a funcionalidade, assumem valor de memória) enquanto património depende de critérios/ /filtros ideológicos e políticos de legitimação, pode ocorrer no contexto original (in situ) ou em lugares que não são os de origem (embora possam estar relacionados com a presença ou decorrer de populações com vínculos aos locais de origem ou a contextos homólogos) e valorizar a dimensão de memória uma vez que "os objetos não são entidades materiais isoladas e inertes que se esgotam em si mesmas, mas sim testemunhos da vida e da cultura em que estão inseridos" (Oliveira, 1988: 3, citado em Chambino, 2009: 4:), isto é apresentam biografias concretas (Brito, 2006), tal como os territórios, e neste sentido são relevantes para os museus. Estes devem valorizar o exterior (território e memória) e sair para fora das suas paredes, ir ao encontro do contexto de génese, dos criadores e utilizadores dos objetos e das paisagens.

Os museus ajudam a reencontrar valor e a atribuir finalidade ou sentido para objetos, equipamentos, infraestruturas, saberes antigos e paisagens que perderam o seu anterior valor de uso ou deixaram de ser operativos (Brito, 2006). O resgate de bens do anonimato, do abandono e do desconhecimento, é também condição para criar património, e assim os museus são guardiães e, ao mesmo tempo, geradores de património.

\section{Notas finais}

O património (natural, cultural e paisagístico) configura um importante recurso (com carácter diferenciador) no contexto dos processos de desenvolvimento dos territórios e das populações. Na amplitude de esferas geográficas diferenciadas assumem crescente visibilidade e relevância as iniciativas relacionadas com os parques (temáticos, biológicos, arqueológicos e geoparques); os centros de interpretação 
(nomeadamente em articulação com as áreas naturais protegidas); os eventos culturais (feiras, festivais, mostras e recriações históricas); os estatutos de proteção (nacionais e internacionais) e classificação de lugares; os lazeres turísticos (em particular os domínios cultural, ecológico, natureza, touring cultural e paisagístico, industrial, arqueológico, passeios pedestres, percursos e centros de BTT, jardins) através de lugares, rotas, circuitos e redes; os museus, as casas-museus e os núcleos museológicos, entre outras.

O conceito atual de museu reflete realidades com uma grande amplitude e diversidade (temática, territorial, organizacional e tutorial) cujos principais traços evolutivos estão desenhados sobretudo nas últimas décadas.

Em linha com as principais mudanças sociais da pós-modernidade, os museus têm de encontrar novas formas de relacionar com o público, captar mercados, comunicar, apresentar o espólio e definir as temáticas de maior interesse (Anico, 2008), ao mesmo tempo que "inseridos numa sociedade capitalista, e dependentes da sua sustentabilidade financeira, conscientes da sua nova missão na sociedade, acrescentam nas suas valências, restaurantes, bares e lojas de merchandising, mostrando preocupação na captação de mais recursos financeiros e de fazer permanecer o visitante mais tempo no museu" (Mendes, 2011: 94). A integração dos museus na cadeia de valor do turismo é uma questão cada vez mais central, uma vez que é reconhecida a importância do museu como atração turística (Prentice, 1993; Silberberg, 1995; Hernández e Tresseras, 2001; Gonçalves, 2010).

Em Portugal, apesar das dificuldades que decorrem dos diferentes critérios que estão na base da recolha e publicação de dados estatísticos sobre os museus, é opinião aceite a de que o número de museus tem vindo a crescer e a diversificar as temáticas e os territórios de intervenção em resultado de iniciativas que envolvem tutelas e meios de financiamento muito diversos, desde programas na área da cultura e do turismo até instrumentos de desenvolvimento rural ou mesmo de apoio a intervenções de valorização ou requalificação de margens ribeirinhas com a manutenção de paisagens rurais e a sua recuperação/valorização para utilizações de características lúdicas e culturais.

Como refere Brito (2006), citado em Chambino (2007: 24-26), os territórios rurais em profunda transformação podem ser apreendidos em quatro planos ou formas de expressão, na perspetiva de intervenção 
dos museus e das formas de patrimonialização, a saber: a configuração física do espaço, as construções (um dos primeiros e mais importantes registos da materialidade de uma cultura), os saberes-fazeres (que é o domínio com maior representatividade nos museus com espólio etnográfico) e, ainda, os usos da palavra, as artes performativas e os rituais.

Ao mesmo tempo, é necessário explicar que as dimensões etnográficas e antropológicas são as mais significativas nos museus rurais em Portugal e estas não estão na primeira linha da atenção para a esmagadora maioria dos visitantes, pelo menos a avaliar pelos dados publicados pelo Instituto Nacional de Estatística através das "Estatísticas da Cultura, 2010", em que os Museus de Etnografia e Antropologia representam apenas 2,4\% do total dos visitantes (quase 14 milhões) dos Museus, Jardins Zoológicos, Botânicos e Aquários - na mesma fonte, os Museus de Território correspondem a 2,6\% e os Museus de História representam $16,4 \%$ do referido universo de visitantes.

Á guisa de conclusão, importa sublinhar que os exemplos apresentados nesta reflexão exploratória demonstram que, para além de funções tradicionais (recolha e preservação patrimonial), os museus e os espaços museológicos rurais apresentam, de forma mais ou menos desenvolvida, funções de investigação e comunicação, bem como ações de promoção do desenvolvimento das comunidades em que se inserem e, em alguns casos, da sua participação nas dinâmicas museológicas (SOUSA, 2010), e integram de forma crescente salas de exposições (permanentes e temporárias), centros de documentação, lojas, serviços de cafetaria/restauração, atividades formativas e pedagógicas, entre outras, que, assim, complementam a sua oferta e correspondem aos interesses renovados dos visitantes (cada vez mais interessados em participar e interagir no museu e no seu contexto territorial).

\section{Referências bibliográficas}

AMADO, Marta (2011) - O Museu do Pão em Seia. Uma iniciativa de desenvolvimento local de expressão nacional. Dissertação de Mestrado em Geografia Humana. Ordenamento do Território e Desenvolvimento apresentada à Faculdade de Letras da Universidade de Coimbra. 
AMIROU, R. (2000) - Imaginaire du tourisme culturel, Col. "La politique éclatée". Paris, PUF.

ANICO, M. (2008) - Museu e Pós-Modernidade. Lisboa, Instituto Superior de Ciências Sociais e Políticas.

BORG, J. van der (2008) - "Towards a policy agenda for tourism development of cultural heritage resources". In JANSEN-VERBEKE, M. et al. (ed.): Cultural Resources for Tourism. Patterns, Processes and Policies. New York, Nova Science Publishers, pp. 245-256.

BRANDÃO, J. M. (2011) - "Ecos: Lousal, do minério às tecnologias". Resumos do II Ciclo de Conferências Cultura a Sul. Évora, CIDEHUS-Universidade de Évora.

BRITO, J. Pais de (2003) - "Museus, memória e projecto". In PORTELA, J.; CALDAS, J. C. (org.): Portugal Chão. Oeiras, Celta Editora. pp. 265-277.

BRITO, J. Pais de (2006) - "Patrimónios e Identidades. Adifícil construção do presente". In PERALTA, E.; ANICO, M. (org.): Patrimónios e Identidades. Ficções Contemporâneas. Oeiras, Celta Editora.

CARVALHO, P. (2002) - "El Patrimonio y el Paisaje Rural en la $(\mathrm{Re})$ construcción de las Memorias e Identidades. Reflexión en torno de algunas iniciativas e propuestas ecomuseológicas en la Cordillera Central Portuguesa". Actas del XI Coloquio de Geografía Rural (Los espacios rurales entre el hoy y el mañana), Santander, Universidad de Cantabria, Servicio de Publicaciones, pp. 89-100.

CARVALHO, P. (2003) - "Património Cultural e Iniciativas de Desenvolvimento Local no Espaço Rural". In CAETANO, L. (coord.): Território, do Global ao Local e Trajetórias de Desenvolvimento. Coimbra, Centro de Estudos Geográficos, pp. 199-227.

CARVALHO,P.(2010) - “Turismo cultural, património e políticas públicas em contextos rurais de baixa densidade: eixos vertebradores de revitalização e de construção de novas identidades?". In SANTOS, G. (org.): Turismo Cultural, Territórios e Identidades. Lisboa, Edições Afrontamento e Instituto Politécnico de Leiria, pp. 123-140.

CARVALHO, P. (2011) - "A AIBT do Pinhal Interior e as Aldeias do Xisto: novos caminhos para o desenvolvimento de territórios de baixa densidade em ambientes de montanha". Cadernos de Geografia, Coimbra, Departamento de Geografia (Universidade de Coimbra) e Centro de Estudos de Geografia e Ordenamento do Território, no 28/29 (2009/2010), pp. 185-191. 
CARVALHO, P. (2012) - "Património e desenvolvimento em ambiente rural: lugares, rotas e redes". Cadernos de Geografia, Coimbra, Departamento de Geografia (Universidade de Coimbra) e Centro de Estudos de Geografia e Ordenamento do Território, $n^{\circ} 30 / 31$, (2011/2012) - em publicação.

CHAÍNHO, P. L. M. (2011) - Gestão e programação do Museu Mineiro do Lousal: o Museu polinucleado do Lousal. Dissertação de Mestrado em Gestão e Programação do Património Cultural apresentada à Faculdade de Letras da Universidade de Coimbra.

CHAMBINO, E. (2009) - Objectos de pastor: do objecto património ao paradoxo da sua insignificância. Dissertação de Mestrado em Antropologia (Especialidade em Patrimónios e Identidades) apresentada ao ISCTE (Lisboa).

CHIVA, I. (1997) - "Le patrimoine rural". In NORA, P. (dir.): Science et Conscience du Patrimoine. Actes des Entretiens du Patrimoine, Éditions du Patrimoine, pp. 226-231.

CLAVAL,P.(2007) - "Changing conceptions of heritage and landscape". In MOORE, N. and WHELAN, Y. (eds.): Heritage, Memory and the Politics of Identity. New Perspectives on the Cultural Landscape. Aldershot, Ashgate, pp. 85-94.

DEWAILLY, J. M. (1998) - "Images of heritage in rural regions". In BUTLER, R. et al. (eds.): Tourism and recreation in rural area, Chichester, John Wiley \& Sons.

DOWER, M. (1998) - "Um trunfo para o desenvolvimento local: o recurso património". LEADER Magazine, 12.

FERREIRA, M. L. (2011) - As rotas culturais - âncoras da ludificação, atractividade e reconversão dos espaços rurais: a rota do românico do Vale do Sousa. Dissertação de Mestrado em Turismo apresentada à Faculdade de Letras do Porto.

FILIPE, G. (1998) - "Ecomuseu Municipal do Seixal - das realizações aos problemas actuais na perspectiva do desenvolvimento local". Actas do VII Encontro Nacional de Museologia e Autarquias. Seixal, Câmara Municipal do Seixal, pp. 173-195.

GARRIGÓS, R. C. (1998) - La gestión y el gestor del patrimonio cultural, Murcia, Editorial KR.

GONÇALVES, A. R. (2010) - "Museus, comunidade local e turismo". In SANTOS, G. (org.): Turismo Cultural, Territórios e Identidades. 
Lisboa, Edições Afrontamento e Instituto Politécnico de Leiria, pp. 81-102.

HERNÁNDEZ, J.; TRESSERAS, J. (2001) - Gestión del Patrimonio Cultural. Barcelona, Ariel.

HAMRIN, O. (1996) - "The Bergslagen ecomusem - from idea to reality". Nordisk Museology, 2, 27-34.

HUDSON, K. (1996) - "Ecomuseums become more realistic". Nordisk Museology, 2, 11-20.

INE (2011) - Estatísticas da Cultura, 2010. Lisboa, Instituto Nacional de Estatística (INE).

KEAMEY, A. (2009) - "Intangible Heritage. Global awareness and local interest". In SMITH, L. and AKAGAWA, N. (eds.): Intangible Heritage. Routledge, London and New York, pp. 209-225.

LIFECOOLER (2012) - Museu do Papel. In http://www.lifecooler.com/ Portugal/patrimonio/MuseudoPapel (último acesso: 23/06/2012)

LIFECOOLER (2012) - Museu de Lanifícios. In http://www.lifecooler. com/edicoes/lifecooler/desenvRegArtigo.asp?reg=334931 (último acesso: 23/06/2012).

LOWENTHAL, D. (1998) - The heritage crusade and the spoils of history. Cambridge, Cambridge University Press.

JORGE, V. Oliveira (2001) - Ambiente, Cultura e Desenvolvimento. Porto, ADECAP.

MENDES, V. (2011) - Museus e turismo na Serra da Estrela. Dissertação de Mestrado em Lazer, Património e Desenvolvimento apresentada à Faculdade de Letras da Universidade de Coimbra.

MOYANO ESTRADA, E. (2006) - "Nuevas orientaciones de la política europea de desarrollo rural. A propósito del Nuevo Regulamento de Desarrollo Rural". Actas del VI Coloquio Ibérico de Estudios Rurales. Huelva, Universidade Internacional de Andaluzia, Huelva, $21 \mathrm{pp}$.

PEREIRA, P. (2000) - "La musealización del patrimonio edificado. Algunos exemplos". In NOLASCO, M. L. (coord.): Museos y museología en Portuga", (RDM; monografías, 01), Madrid, Asociación Española de Museólogos, 119-125.

PESSOA, F. (2001) - Reflexões sobre Ecomuseologia, Col. "Viver é Preciso" no 20. Porto, Edições Afrontamento.

PRENTICE, R. (1993) - Tourism and Heritage Attractions. New York, Routledge. 
PUENTE FERNÁNDEZ, L. (2011): "El valor patrimonial del paisaje: cultura, medioambiente y democracia". Proceedings of 6th International Congress for Spatial Planning. Madrid, FUNDICOT, pp. 211-225

PRIMO, J. (1999) - "Pensar contemporaneamente a museologia". Cadernos de Sociomuseologia, 16, Lisboa, Universidade Lusófona de Humanidades e Tecnologias.

RAFAEL, L. (2010) - Os trinta anos do projecto vila museu: balanço e perspectivas. Dissertação de Mestrado em Museologia apresentada à Universidade de Évora.

RIVIÈRE, G. Henri (1989) - La Muséologie, Paris, Bordas (trad. cast., La Museología, trad. de Antón Rodríguez Casal, Akal, 1993).

SANTOS, L. A. (2009) - Proposta de musealização de Fornos de Carvão Vegetal, Torres Vedras. Dissertação de Mestrado em Museologia apresentado ao ISCTE (Lisboa).

SILBERBERG,T. (1995) - "Cultural tourism and business opportunities for museums and heritage sites. Tourism Management, vol. 16 (5), pp. 361-365.

SMITH, L. (2006) - Uses of Heritage. Routledge, London and New York, pp. 11-43.

SOUSA, S. M. (2010) - A museologia na ilha de São Miguel: 1974-2008. Dissertação de Mestrado em Património, Museologia e Desenvolvimento apresentada à Universidade dos Açores.

TEIXEIRA, D. V. (2006) - O Ecomuseu de Barroso: a nova museologia ao serviço do desenvolvimento local. Dissertação de Mestrado em Património e Turismo apresentada à Universidade do Minho. 